ANA PAULA BRESSANI PEIXOTO BARBOZA

\title{
Poderes do juiz e garantismo processual
}

\author{
Dissertação de Mestrado \\ Orientador: Professor Associado Dr. Antonio Carlos Marcato
}

\section{UNIVERSIDADE DE SÃO PAULO}

FACULDADE DE DIREITO

São Paulo - SP 



\section{ANA PAULA BRESSANI PEIXOTO BARBOZA}

\section{Poderes do juiz e garantismo processual}

Dissertação apresentada à Banca Examinadora do Programa de Pós-Graduação em Direito, da Faculdade de Direito da Universidade de São Paulo, como exigência parcial para obtenção do título de Mestre em Direito, na área de concentração Direito Processual Civil, sob a orientação do Professor Associado Dr. Antonio Carlos Marcato.

UNIVERSIDADE DE SÃO PAULO

FACULDADE DE DIREITO

São Paulo - SP 
Serviço de Processos Técnicos da Biblioteca da Faculdade de Direito da Universidade de São Paulo

Barboza, Ana Paula Bressani Peixoto

Poderes do juiz e garantismo processual / Ana Paula Bressani Peixoto Barboza. -- São Paulo, 2020.

106 p.; $30 \mathrm{~cm}$.

Dissertação (Mestrado) - Programa de Pós-Graduação em Direito, Faculdade de Direito, Universidade de São Paulo, São Paulo, 2020.

Orientador: Antonio Carlos Marcato.

1. Processo Civil; 2. Garantismo processual; 3. Constituição e processo; 4. Poderes do juiz; 5. Iniciativa probatória do juiz. I. Marcato, Antonio Carlos, orient. II. Título. 
Nome: BARBOZA, Ana Paula Bressani Peixoto

Título: Poderes do juiz e garantismo processual

Dissertação apresentada à Faculdade de Direito da Universidade de São Paulo como exigência parcial para obtenção do título de Mestre em Direito.

Aprovado em: Banca Examinadora

\section{Orientador}

Prof. Associado Dr. Antonio Carlos Marcato

Prof. Dr. Instituição:

Julgamento:

Assinatura:

Prof. Dr. Instituição:

Julgamento: Assinatura:

Prof. Dr. Instituição:

Julgamento: Assinatura: 

Aos meus pais, Guilherme, Olivia e Clara, com amor. 



\section{AgRadecimentos}

Agradeço, em primeiro lugar, ao meu orientador, Professor Dr. Antonio Carlos Marcato, pela oportunidade de aprofundar meus estudos na pós-graduação da melhor Faculdade de Direito do país, pelos muitos ensinamentos, paciência e apoio. É realmente inspirador!

Agradeço aos meus pais que, conhecendo pouco de ciência, sempre acreditaram nos meus sonhos e cuidaram da minha educação. Vocês são meus maiores exemplos de integridade e bondade. Todas as minhas conquistas são primeiramente de vocês e para vocês!

Agradeço, em especial, ao meu querido marido Guilherme pelos constantes incentivos, por estar comigo nesse projeto e, com amor, me acompanhar em cada momento. Minha maior felicidade é compartilhar a vida com você e com as nossas meninas, Olivia e Clara.

Clarinha, minha filha, tudo é infinitamente melhor desde que você chegou! Você é meu amor maior! Obrigada por ser e estar com a Mamãe nesse momento especial.

Ao Machado Meyer, minha casa desde o segundo ano da faculdade. À Gláucia Mara Coelho pelo apoio desde que soube de minha inscrição no processo seletivo da pósgraduação para aprofundamento dos estudos de Direito Processual. À Eliane Cristina Carvalho e ao Paulo Eduardo Leite Marino pelo prazeroso convívio do dia a dia, debates enriquecedores e muitos ensinamentos. Com o mesmo carinho, agradeço os demais amigos do escritório e minha equipe. 



\section{RESUMO}

BARBOZA, Ana Paula Bressani. Poderes do juiz e garantismo processual. 2020. 106 p. Dissertação (Mestrado) - Faculdade de Direito, Universidade de São Paulo, São Paulo, 2020.

O presente trabalho é um estudo sobre as garantias constitucionais do processo e os poderes instrutórios do juiz. Em sintonia com a ciência processual moderna, defende-se que o juiz, representante estatal, tem amplos poderes para participar da instrução do processo e determinar a produção das provas que entender necessárias para julgamento da relação de direito material controvertida. No primeiro capítulo, serão definidos os institutos fundamentais da doutrina clássica do processo, ou seja, os conceitos de jurisdição, processo, ação e defesa. Feito isso, no segundo capítulo, passa-se à análise da teoria do garantismo processual e dos princípios constitucionais do processo. No terceiro capítulo, aborda-se o conceito de prova e a natureza constitucional do direito de prova. Por fim, no quarto capítulo, investiga-se os poderes do juiz na atividade instrutória para formação do conjunto probatório. Com isso, sem negar que o processo é instrumento para resolução de conflitos do direito material, será possível debater a natureza pública da relação processual, o interesse público da atuação do ordenamento jurídico e a amplitude dos poderes instrutórios do juiz para o melhor resultado possível da atividade jurisdicional.

Palavras-chave: 1. Processo Civil; 2. Garantismo processual; 3. Constituição e processo; 4. Poderes do juiz; 5. Iniciativa probatória do juiz. 



\begin{abstract}
BARBOZA, Ana Paula Bressani Peixoto. Powers of the judge and garantism in the civil proceedings. 2020. 106 p. Dissertation (Master) - Law School, University of São Paulo, São Paulo, 2020.

The present work is a study about the procedural constitutional rights and the leading powers of the judge. In line with the modern procedural science, it is argued that the judge, a state representative, has broad powers to participate in the investigation of the case and to determine the collection of the evidence he deems necessary for the judgment of the disputed substantive law relationship. In the first chapter, the fundamental institutes of classical process doctrine will be determined, namely the concepts of jurisdiction, process, lawsuit and defense. After that, in the second chapter, we will proceed to the analysis of the theory of garantism in civil proceedings and the constitutional due process principles. In the third chapter, the concept of evidence and the constitutional nature of the right to prove will be addressed. Finally, in the fourth chapter, the powers of the judge in the leading activity while constructing the set of proofs are investigated. With this, without denying that the process is an instrument for solving conflicts arising from material law, it will be possible to debate the public nature of the procedural relationship, the public interest in the enforceability of the legal framework and the extent of the judge's leading powers for towards the best possible outcome in the jurisdictional activity.
\end{abstract}

Key words. 1. Civil Procedure; 2. Garantism in civil proceedings; 3. Constitution and process; 4. Powers of the judge; 5. Evidence of the judge. 



\section{LISTA DE ABREVIATURAS E SIGLAS}

$\begin{array}{ll}\text { CDC } & \text { Código de Defesa do Consumidor (lei n. 8.078/90) } \\ \text { CF } & \text { Constituição da República Federativa do Brasil de } 1988 \\ \text { CPC/15 } & \text { Código de Processo Civil de } 2015 \text { (lei n. 13.105/2015) } \\ \text { CPC/73 } & \text { Código de Processo Civil de } 1973 \text { (lei n. 5.869/1973) } \\ \text { CPC/39 } & \text { Código de Processo Civil de } 1939 \text { (lei n. 1.608/1939) } \\ \text { CPC/16 } & \text { Código de Processo Civil de } 1916 \text { (lei n. 3.071/1916) } \\ \text { REsp } & \text { Recurso Especial } \\ \text { RHC } & \text { Recurso Ordinário em Habeas Corpus } \\ \text { STJ } & \text { Superior Tribunal de Justiça } \\ \text { STF } & \text { Supremo Tribunal Federal }\end{array}$




\section{SUMÁRIO}

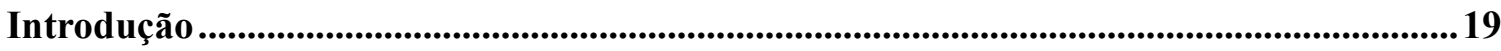

Capítulo 1 - Os institutos fundamentais do processo civil ..............................................23

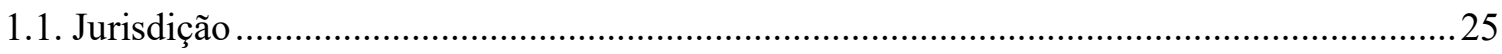

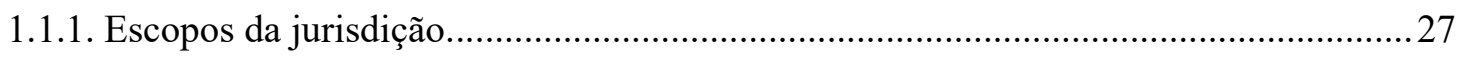

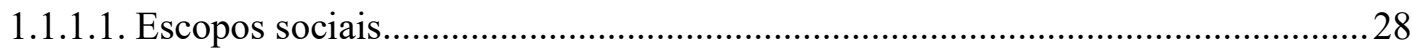

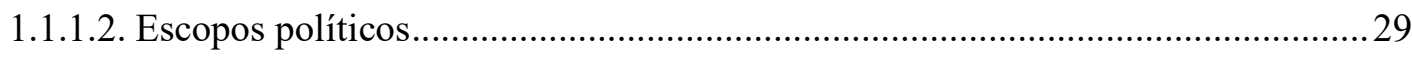

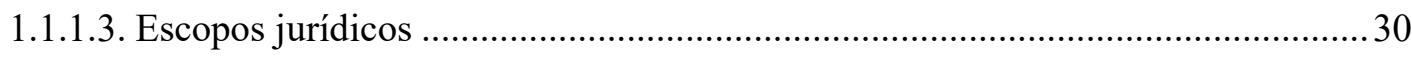

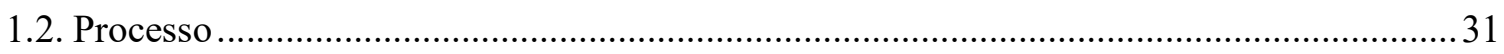

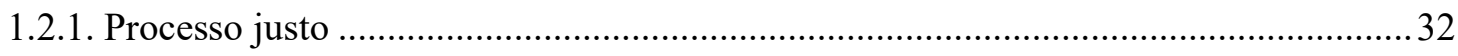

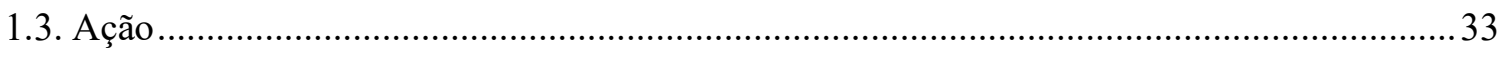

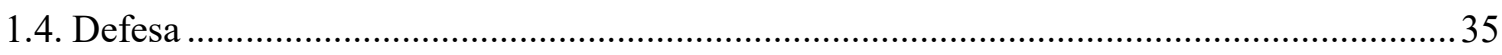

1.5. Concepção privatista e publicista do processo e da ação .................................................... 36

Capítulo 2 - A teoria do garantismo processual.................................................................................38

2.1. Direito Processual Constitucional x Direito Constitucional Processual............................. 42

2.2. A cláusula geral do devido processo legal: uma garantia síntese ......................................44

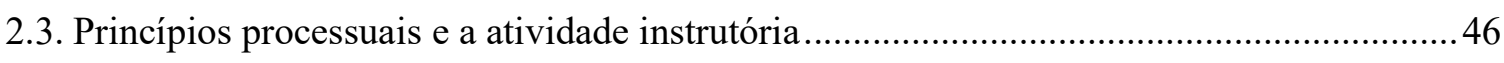

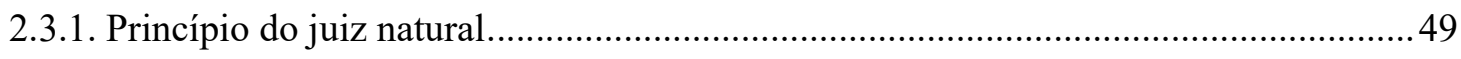

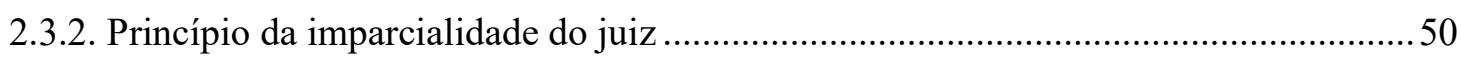

2.3.3. Princípio da demanda e inércia da jurisdição ..........................................................51

2.3.4. Princípios do contraditório e da ampla defesa ...........................................................52

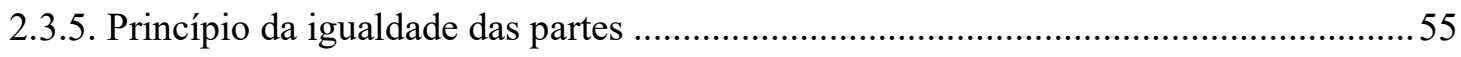

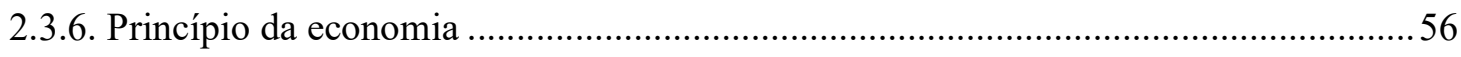

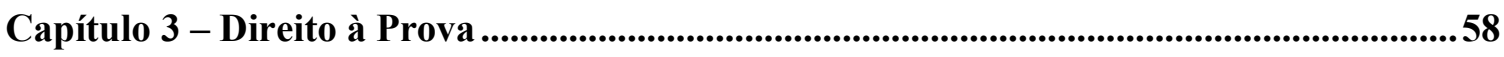

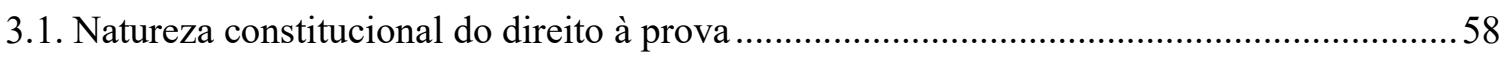

3.2. Produção probatória, direito das partes e dever do órgão jurisdicional ..............................59

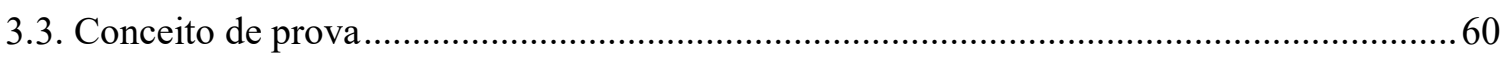

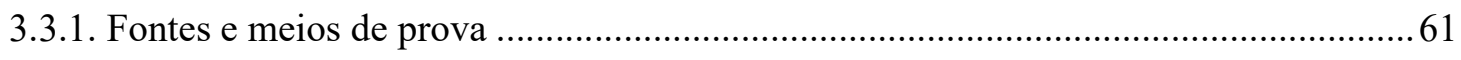

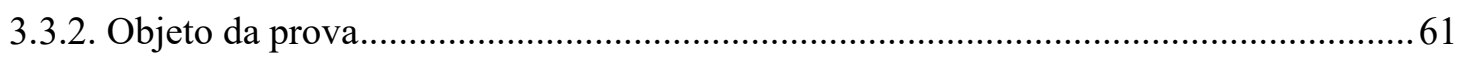

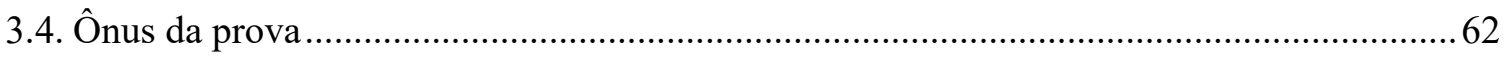

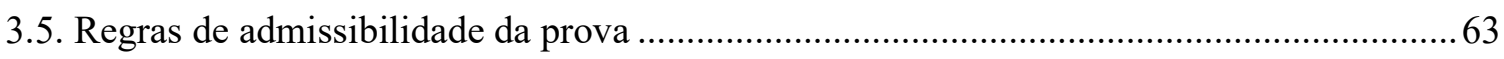

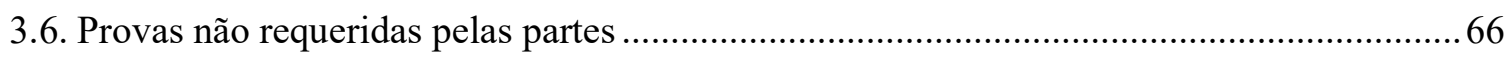




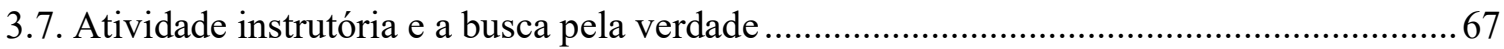

3.8. Atividade instrutório e os princípios inquisitivo e dispositivo ............................................. 69

Capítulo 4 - O papel ativo do juiz na condução do processo ...................................................73

4.1. A persuasão racional do juiz, a motivação e a publicidade das decisões judiciais .............77

4.2. Atividade instrutória, imparcialidade do juiz e igualdade processual ................................78

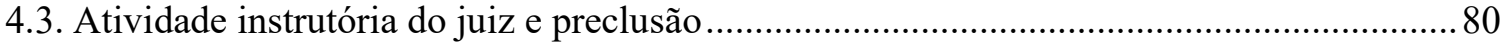

4.4. Atividade instrutória do juiz e a disponibilidade do direito material .................................. 80

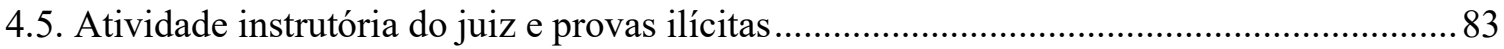

4.6. Atividade instrutória do juiz e as regras do ônus da prova.................................................. 85

4.7. Participação ativa do juiz na instrução probatória e regimes autoritários ............................ 87

4.8. Mecanismos de controle e limites dos poderes instrutórios conferidos ao juiz .................. 89

4.9. A postura ativa do juiz e eficiência de resultados do processo ..........................................90

Conclusão ..........................................................................................................................................................93

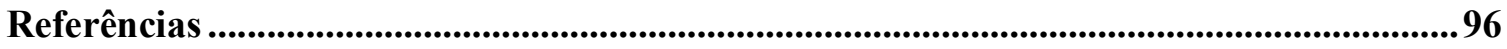





\section{INTRODUÇÃO}

O fenômeno do garantismo processual acentua o vínculo indissociável entre Constituição e processo $^{1}$. O garantismo é uma doutrina filosófica, política e jurídica, com raízes no Iluminismo do século XVIII, voltada à preservação dos direitos e garantias dos cidadãos por meio do equilíbrio entre a atuação do Estado e dos particulares para conferir efetividade às normas jurídicas ${ }^{2}$.

Em meio a muitas visões sobre o fenômeno processual, diversas teorias e diferentes formas de se pensar e compreender o direito e a técnica processual, cada uma com importância e proposições metodológicas próprias, a evolução da ciência processual reconhece a imprescindibilidade de observância das garantias constitucionais como premissa central de estudo ${ }^{3}$, da qual se associa a participação proativa, cooperativa e responsável de todos os sujeitos na condução do processo, as partes e o juiz, para viabilizar que os litígios sejam solucionados da forma mais célere, justa $^{4}$, efetiva ${ }^{5}$, menos custosa ${ }^{6}$ e mais próxima da

1. O fenômeno do "Stato costituzionale" foi abordado por Gustavo Zagrebelsky (In Il diritto mite, Torino, Einaudi, 1992, p. 39. Nesse mesmo sentido, Antônio Carlos de Araújo Cintra, da Pellegrini Grinover e Cândido Rangel Dinamarco tratam do "processo constitucional” (In Teoria Geral do Processo, 30 ed., p. 98).

2. O trabalho do professor italiano Luigi Ferrajoli foi determinante para uma visão ampla e sistemática da teoria do garantismo processual. A teoria do garantismo processual, ousada para a época, buscava um sistema geral que garantisse as liberdades do indivíduo frente às mais variadas formas de atuação do Estado e seu exercício de poder (In: Derecho y rázon: teoria del garantismo penal (com prologo de Norberto Bobbio)).

3. Conforme enfatiza Luís Roberto Barroso, “o constitucionalismo foi o projeto político vitorioso ao final do milênio. A proposta do minimalismo constitucional, que procura destituir a Lei maior de sua dimensão política e axiológica, para reservar-lhe um papel puramente procedimental, não é compatível com as conquistas do processo civilizatório" (In Fundamentos teóricos e filosóficos do novo direito constitucional brasileiro: pós modernidade, teoria crítica e pós-positivismo, p. 46).

4. Considera-se o processo não sob a ótica do resultado para as partes, mas sob a ótica de sua construção, de modo que é o processo deve ser considerado justo quando o Estado atua com observância das garantias constitucionais estabelecidas, em cada país, em ordem constitucional. O conceito de processo justo é variável conforme os contextos sociopolíticos de cada país.

5. Ensina José Roberto dos Santos Bedaque que "A ideia de efetividade do processo está relacionada com o cumprimento de modo eficiente, do escopo reservado a esse método de trabalho, qual seja, a realização prática das normas de direito material não observadas espontaneamente. (Instrumentalismo e garantismo: visões opostas do fenômeno processual? In: Garantismo processual: garantias constitucionais aplicadas ao processo, p. 32). No mesmo sentido, José Carlos Barbosa Moreira: “Querer que o processo seja efetivo é querer que desempenhe com eficiência o papel que lhe compete na economia do ordenamento jurídico. Visto que esse papel é instrumental em relação ao direito substantivo, também se costuma falar da instrumentalidade do processo. Uma noção conecta-se com a outra e por assim dizer a implica. Qualquer instrumento será bom na medida em que sirva de modo prestimoso à consecução dos fins da obra a que se ordena, em outras palavras, na medida em seja efetivo. Vale dizer: será efetivo o processo que constitua instrumento eficiente de realização do direito material". (Por um processo socialmente efetivo. In: Temas de direito processual, p. 15).

6. Interessante observar que a dimensão temporal do processo não pode ser compreendida como um valor em sim, isolada da efetividade dos resultados, do custo do processo. Antonio Carlos Marcato apresenta a crítica de Pondera Vigoriti sobre a ausência de doutrina acerca de problemas relacionados ao custo do processo e à 
verdade real possível ${ }^{7}$. Nessa linha, o processo civil não deve ser indiferente à veracidade dos fatos e não pode se sucumbir aos interesses privados da parte como se fosse um jogo de azar, em que ganha o participante mais perspicaz.

Ao mesmo tempo em que o garantismo apresenta-se como doutrina que combate o ativismo judicial ${ }^{8}$, é com base nas garantias constitucionais, para assegurar a integridade do ordenamento jurídico, que a ciência processual moderna se fundamenta para ampliar a participação do juiz na formação do conjunto probatório e garantir o contraditório real entre os litigantes.

A presença de regras, princípios e garantias de direito processual no texto constitucional confere ao conteúdo das normas processuais e, por consequência, aos litigantes, a segurança jurídica diferenciada da permanência e preeminência típica das normas de direito constitucional ${ }^{9}$.

O denominado "modelo constitucional do processo"10, consistente na apresentação de um conjunto mínimo de regras processuais no texto constitucional, implica que o legislador infraconstitucional observe tal programa na elaboração das leis e, da mesma forma, que o juiz interprete e aplique as leis processuais tendo como premissa o quadro constitucional delineado com a regulação do processo e do procedimento ${ }^{11}$.

duração do processo que, na tentativa de entender as razões, pondera que os critérios são estranhos à ciência jurídica e exigiram conhecimentos econômicos e estatísticos complexos, na maioria das vezes, estranhos aos estudiosos de Direito em sua maioria (In Algumas considerações sobre a crise da justiça, pp.7-8).

7. Como ensina Cândido Rangel Dinamarco "O juiz há de contentar-se com a probabilidade, renunciando à certeza, porque o contrário inviabilizaria os julgamentos” (In A instrumentalidade do processo, p. 318-319).

8. Por força do recorte adotado nesta dissertação, não abordaremos os variados entendimentos e problemáticas sobre o ativismo judicial. Utilizaremos o conceito adotado por Elival da Silva Ramos, "Por ativismo judicial deve-se entender o exercício da função jurisdicional para além dos limites impostos pelo próprio ordenamento que incumbe, institucionalmente, ao Poder Judiciário fazer atuar, resolvendo litígios de feições subjetivas (conflitos de interesse) e controvérsias jurídicas de natureza objetiva (conflitos normativos). Há como visto, uma sinalização claramente negativa no tocante às práticas ativistas, por importarem na desnaturação da atividade típica do Poder Judiciário, em detrimento dos demais Poderes. Não se pode deixar de registrar mais uma vez que o fenômeno golpeia mais fortemente o Poder Legislativo, o qual tanto pode ter o produto na legiferação irregularmente invadido por decisão ativista (em sede de controle de constitucionalidade), quanto o seu espaço de conformação normativa invadido por decisões excessivamente criativas." (In Ativismo Judicial: parâmetros dogmáticos. São Paulo, p. 129).

9. No Brasil, conforme artigo $60, \S 4^{\circ}$, inciso IV da CF, é necessário pontuar que "os direitos e as garantias individuais" são cláusulas pétreas e não serão objeto de deliberação de proposta de emenda à Constituição.

10. Sobre o tema, destacam-se as obras de Antônio Carlos de Araújo Cintra, Ada Pellegrini Grinover e Cândido Rangel Dinamarco (In Teoria Geral do Processo, p. 97); Cândido Rangel Dinamarco (In Instituições de Direito Processual, t. I, p. 185-192); Carlos Alberto Alvaro de Oliveira e Daniel Mitidiero(In Curso de direito processual, p. 16-17); Cássio Scarpinella Bueno (In Curso sistematizado de direito processual civil, v. 1, p. 92 e ss).

11. Cândido Rangel Dinamarco comenta que "o modelo constitucional do processo civil brasileiro é acentualmente garantístico, no duplo sentido de que toda a vida do processo civil deve necessariamente ser permeada da mais estrita fidelidade aos princípios ditados na Constituição Federal; e de que o sistema processual inclui medidas de tutela específica destinadas à preservação das liberdades e dos valores da cidadania" (In Instituições de Direito Processual, t. I, p. 186) 
Paralelamente, verifica-se também que as normas constitucionais passam a ser replicadas nos mais diversos diplomas legislativos. O modelo prestigiado pelo CPC/2015, seguindo essa tendência, traz um capítulo introdutório sobre as Normas Fundamentais do Processo Civil ${ }^{12}$. A despeito de muitas críticas que podem ser feitas ao novo diploma processual, é necessário reconhecer que o CPC/2015, a começar pelo capítulo de apresentação dos conceitos constitucionais, expressa uma concepção de sistema processual que reafirma o garantismo processual e exige de todos os sujeitos uma postura mais cooperativa, responsável e proativa na formação do provimento jurisdicional.

Ao compreender a atividade jurisdicional como exercício do poder estatal e, nesse contexto, os poderes instrutórios conferidos ao juiz no fenômeno processual como mecanismo de equilíbrio de eventuais desigualdades econômicas e culturais dos litigantes, privilegia-se o interesse público envolvido nas decisões judiciais para a correta solução do litígio e a pacificação social, que são finalidades da atividade jurisdicional ${ }^{13}$.

Tornam-se, assim, cada vez mais frequentes os debates sobre a postura ativa e a participação colaborativa do julgador na formação do conjunto probatório e na condução do processo.

Para início da abordagem, o primeiro capítulo traz as definições de jurisdição, processo, ação e defesa. Na sequência, no segundo capítulo, o exame da teoria do garantismo processual para ressalvar o vínculo indissociável que deve existir entre os institutos processuais e as garantias constitucionais.

No terceiro capítulo, analisar-se-á os temas da teoria da prova como o conceito de prova, as fontes e os meios de prova, o objeto da prova, o requerimento de provas pelas partes, a determinação de provas por iniciativa do juiz, a admissão da prova pelo juiz, a avaliação da prova e os momentos da prova, com o enfoque da atividade instrutória voltada à busca da verdade real ou máximo grau de probabilidade dos fatos para formação do convencimento do julgador.

O capítulo final tratará do papel ativo do juiz na atividade instrutória. Além de abordar a instrução probatória como direito dos litigantes e dever do juiz, buscar-se-á esclarecer, sob uma perspectiva sistemática, a adequação da atividade instrutória do juiz com

12. O Capítulo I do CPC/2015, nos artigos $1^{\mathrm{o}}$ ao $6^{\mathrm{o}}$, apresenta as Normas Fundamentais do Processo Civil e confirma o fenômeno recente de constitucionalização das normas.

13. Sobre o tema, escreve José Carlos Barbosa Moreira: “Ao juiz compete, sem dúvida, respeitá-los (interesses privados em jogo) e fazê-los respeitar; todavia, não é só isso que lhe compete. Incumbe-lhe dirigir o processo de tal maneira que ele sirva bem àqueles a quem se destina servir. E o processo deve, sim, servir às partes; mas deve também servir à sociedade". (O processo, as partes e a sociedade, p. 40). 
o processo civil de resultados, observados os princípios da motivação e publicidade das decisões, a imparcialidade do juiz, e sua interface com outros institutos da técnica processual como a preclusão, a disponibilidade ou indisponibilidade do direito material, a admissibilidade de provas e as regras de distribuição do ônus da prova.

Encerrado esse debate, terão sido assentadas as bases necessárias para se obter conclusão segura e confiável sobre a importância da ampliação dos poderes instrutórios do juiz e da iniciativa probatória oficial no sistema jurídico-processual brasileiro.

Da forma como se pretende abordar a teoria do garantismo processual, demonstrarse-á que as garantias constitucionais do processo são conciliáveis com a postura ativa do juiz na formação do conjunto probatório. Muito além das discussões sobre sistemas processuais em regimes políticos liberais ou autoritários, correntes publicista e privatista da técnica processual, os poderes instrutórios do juiz confirmam a preservação dos interesses das partes e as garantias constitucionais do processo. O papel do juiz não é apenas receber e valorar as provas requeridas pelas partes, mas, sempre que necessário e nos limites legais, participar ativamente da fase instrutória do processo. 


\section{CONCLUSÃo}

As reflexões formuladas nesse trabalho reafirmam a relevância da aplicação do garantismo na técnica processual contemporânea, cujo significado de proteção das liberdades do indivíduo frente ao poder estatal não pode ser minimizado, mas pode e deve ser interpretado de acordo com os escopos sociais, políticos e jurídicos do processo.

Atentos aos efeitos irradiados pelo processo na sociedade e adotando, portanto, as posições de José Roberto do Santos Bedaque ${ }^{235}$, anteriormente adotada por José Carlos Barbosa Moreira ${ }^{236}$ e Moacyr Amaral Santos ${ }^{237}$, exercido o direito de ação e instaurado o processo pela parte, os poderes instrutórios do juiz devem ser amplos para colaborar com a busca da verdade no processo civil e propiciar a prolação de decisões justas para as partes. Ainda que todo o sistema seja construído com base na ampla participação das partes (para apresentação dos pedidos, para exercício da defesa, para alegações e para produção de $\operatorname{provas}^{238}$ ), cresce corretamente a tendência de reforço dos poderes do juiz e seu dever de participação na atividade instrutória.

Em meio a evoluções e discussões sobre o instituto da iniciativa probatória, em termos com o princípio da economia processual, a postura ativa do juiz propicia o máximo resultado na atuação do direito com o equilíbrio do binômio custo-benefício e efetividade do processo na eliminação dos conflitos sociais. Por assim dizer, a vontade dos litigantes não pode ser um limitador à atividade instrutória oficial.

É válido ponderar, no entanto, que a ampliação dos poderes do juiz na evolução da técnica processual não possibilita inovar no processo, tampouco adentrar no campo das liberdades do indivíduo. $\mathrm{O}$ artigo $8^{\circ}$ do $\mathrm{CPC} / 15$, ao estabelecer que "ao aplicar o ordenamento jurídico, o juiz atenderá aos fins sociais e às exigências do bem comum, resguardando e promovendo a proporcionalidade, a razoabilidade, a legalidade, a publicidade e a eficiência", confirma os princípios e garantias constitucionais de que o juiz não pode determinar a produção de provas de acordo com suas crenças e preferências pessoais. Muito pelo contrário, admitir tal comportamento seria aproximar o Poder Judiciário de um regime aleatório e

\footnotetext{
${ }^{235}$. In Poderes instrutórios do juiz, op. cit.

${ }^{236}$. O juiz e a prova. In Revista de processo, n. 35, p. 178-184, ano 9, jul./set. 1984.

${ }^{237}$. In Prova Judiciária no Cível e Comercial, op. cit.

${ }^{238}$. In Instituições de Direito Processual Civil, $8^{\mathrm{a}}$ ed., rev. e atual., v. I, p. 345.
} 
ditatorial, em ofensa ao devido processo legal e às demais regras do país que se afirma Estado Democrático de Direito. A legítima liberdade do juiz está na atuação ponderada e na capacidade de compreender e renovar os valores da sociedade nos casos concretos. Reitera-se, não pelo comportamento arbitrário, mas pelo o comportamento colaborativo para valoração dos casos concretos de acordo com os princípios e valores da sociedade ${ }^{239}$.

A conclusão é de que os poderes do juiz estão intimamente relacionados à observância dos princípios e garantias constitucionais para adequada aplicação da Constituição e da lei, com a prática de atos de direção, de prova e de diálogo no processo. Os atos de direção estão relacionados às responsabilidades de impulso oficial. Os atos de prova à efetiva participação na formação do conjunto probatório. Os atos de diálogo ao pleno exercício do contraditório e viabilização de meios de participação das partes para comprovação das questões de fato e ampla manifestação sobre pontos tidos como controversos.

No mais, a iniciativa probatória oficial retira o juiz de forçada inércia para apuração mais completa dos fatos. É essencial investigar a verdade para que o grau de probabilidade do juiz seja o mais alto possível dos fatos constitutivos, modificativos e extintivos do direito firmado. Ainda, em sentido contrário à tese de que a apuração mais completa dos fatos tornaria o juiz imparcial, é preciso ponderar que seria parcial o juiz que tivesse conhecimento de que determinada prova possibilitaria o esclarecimento de uma questão de fato e opta por não compor o conjunto probatório ${ }^{240}$.

239. Cândido Rangel Dinamarco critica a analogia entre o juiz e maestro para reafirmar que o juiz não tem liberdade para desconsiderar os textos legais e as demais fontes do direito: "Os que veem nessa liberdade interpretativa uma criação jurídica lançam mão de uma imagem muito expressiva e elegante mas irreal, ao compararem o juiz ao maestro condutor de orquestra, em sua liberdade de enriquecer as composições musicais com seus próprios sentimentos e criatividade: uma sintonia de Mozart ou Beethoven não é igual a si mesma quando arranjada ou interpretada por Herbert von Karajan, Claudio Abbado, Zubin Metha ou Lorin Maazel. Mas existe uma grande diferença entre a atividade do juiz e a do maestro-arranjador, dado que este não lida com direitos e obrigações de outras pessoas nem impõe imperativamente a outrem as soluções ditadas por seus gostos pessoais. A maior ou menor fidelidade à composição dos Mestres pode causar impressões sensoriais mais agradáveis ou menos, mas não diminui nem aumenta o patrimônio das pessoas, nem altera o curso de suas vidas. Se o juiz tivesse a mesma liberdade que os maestros têm, estaria comprometido esse sólido pilar do Estado de direito, que é o princípio da legalidade sintetizado na garantia constitucional do due processo flaw (em si mesmo conceituado como sistema de freios e limites ao exercício do poder estatal). A elegante comparação não passa, como se vê, de um astuto expediente dialético de argumentação, sem raízes na realidade." (In Instituições de Direito Processual Civil, $8^{\mathrm{a}}$ ed, rev. e atual., v. I, p. 230).

240. Como bem observa Eduardo Talamini: "Se a reconstituição dos fatos determinada de ofício vem a beneficiar quem tem razão, não há nisso infração ao dever de imparcialidade, mas o adequado cumprimento da função jurisdicional. A imparcialidade se concretiza pela concessão de iguais oportunidades aos litigantes e a consideração mais isenta possível de seus argumentos - e cessa aí. As vantagens que advêm no processo a alguma das partes, precisamente porque e na medida em que esta tem razão, não são mais do que consequência da correta atuação imparcial." (Prova emprestada no processo civil e penal, p. 156). 
A ampla iniciativa probatória oficial é regra do processo civil brasileiro e, ainda que pareça equívoca a associação, coaduna com o garantismo processual por propiciar a observância do contraditório efetivo. Daí, os limites à iniciativa probatória oficial estão na observância do contraditório e na obrigatoriedade de motivação das decisões judiciais impostos pela licitude das $\operatorname{provas}^{241}$.

Assim sendo, a atividade probatória oficial não é excepcional e não substitui o dever das partes de, ao longo do processo, provar os elementos sobre os pontos de fatos incertos no processo. Conforme já dito, a prova pertence a todos os participantes da relação processual e o juiz, sujeito processual interessado na efetividade do processo, deve determinar as provas que entenda necessárias para a correta aplicação da lei e integridade do ordenamento jurídico.

As questões polêmicas discutidas nesse trabalho, como adiantado, não pretendiam esgotar as inúmeras discussões doutrinárias e jurisprudenciais existentes acerca da instrução probatória oficial, mas é certo, e foi reiteradamente pontuado, que os tempos modernos exigem o olhar atento do Estado à utilidade social do processo e a efetividade do direito, sendo a iniciativa probatória do juiz inerente à garantia política do devido processo legal ${ }^{242}$.

241. A respeito, observa Ada Pellegrini Grinover, In A iniciativa instrutória do juiz no processo penal acusatório. Revista Forense 347/3-10.

242. Como observado por José Roberto dos Santos Bedaque, "Para que o processo possibilite real acesso à ordem jurídica justa, necessária a garantia da produção da prova, cujo titular é, em princípio, a parte, mas não exclusivamente ela, pois ao juiz, como sujeito interessado no contraditório efetivo e equilibrado e na justiça das decisões, também assiste o poder de determinar as provas necessárias à formação de seu convencimento. A iniciativa probatória do juiz é elemento indissociável da efetividade do processo." (In Poderes instrutórios do juiz, $4^{\mathrm{a}}$ ed., rev., atual e ampl., p. 24). 


\section{REFERÊNCIAS}

ABDO, Helena. O Abuso no Processo. São Paulo: Revista dos Tribunais, 2008.

AMENDOEIRA JR., Sidnei. Poderes do Juiz e Tutela Jurisdicional: a utilização racional dos poderes do juiz como forma de obtenção da tutela jurisdicional efetiva, justa e tempestiva. In Coleção Atlas de Processo Civil, Carlos Alberto Carmona (Coord.). Atlas: São Paulo, 2006.

ARAÚJO CINTRA, Antônio Carlos de; GRINOVER, Ada Pellegrini e DINAMARCO, Cândido Rangel. Teoria Geral do Processo, 30 ed. rev. atual. aum. São Paulo: Malheiros, 2014.

ARRUDA ALVIM NETTO, José Manoel de. Curso de direito processual civil, v. II, São Paulo: Revista dos Tribunais, 1972.

. Manual de Direito Processual Civil: teoria geral do processo e processo de conhecimento, $17^{\mathrm{a}}$ ed. São Paulo: Revista dos Tribunais, 2017.

ASSIS, Araken de. Processo civil brasileiro - parte geral: fundamentos e distribuição de conflitos, v. I. São Paulo: Revista dos Tribunais, 2015.

. Processo civil brasileiro parte geral: institutos fundamentais, v. II, t. I. São

Paulo: Revista dos Tribunais, 2015.

ÁVILA, Humberto. Teoria dos princípios, $11^{\mathrm{a}}$ ed. São Paulo: Malheiros, 2010.

BADARÓ, Gustavo Henrique Righi Ivahy. Direito à prova e os limites lógicos de sua admissão: os conceitos de pertinência e relevância. In: BEDAQUE, José Roberto dos Santos; CINTRA, Lia Carolina Batista; EID, Elie Pierre (Coords.). Garantismo processual: garantias constitucionais aplicadas ao processo, $1^{\mathrm{a}}$ ed. Brasília, DF: Gazeta Jurídica, 2016.

. Onus da prova no processo penal. São Paulo: Revista dos Tribunais, 2003.

BARBIERI, Mauricio Lindenmeyer. Implicações do princípio dispositivo nos poderes instrutórios do juiz. In: OLIVEIRA, Carlos Alberto Álvaro de (org.), Prova cível. Rio de janeiro: Forense, 1999.

BARBOSA MOREIRA, José Carlos. A Constitucionalização do Processo no Direito 
Brasileiro. In: MAC-GREGOR, Eduardo Ferrer; LARREA, Arturo Zaldívar Lelo de (Coords.). Estudos de direito processual constitucional - Homenagem Brasileira à Hector Fix-Zamudio em seus 50 anos como Pesquisador do Direito, 2009, p. 55.

. A função social do processo civil moderno e o papel do juiz e das partes na direção e na instrução do processo. RePro 37/140.

. Comentários ao Código de Processo Civil, v. V (arts. 476 a 565), 14ª ed. Rio de Janeiro: Forense, 2008.

. Correntes e contracorrentes no processo civil contemporâneo: um enfoque. Temas de direito processual. 9a série. São Paulo: Saraiva, 2007.

. "Efetividade do processo e técnica processual". In: Revista de Processo, v. 77/1995, jan.-mar./1995.

. "Notas sobre o problema da "efetividade do processo". In: Temas de Direito Processual Civil (Terceira Série). São Paulo: Saraiva, 1984.

. O juiz e a prova. In: Revista de Processo, n. 35, ano 9, jul./set. 1984.

- “O problema da 'divisão do trabalho' entre juiz e partes: aspectos terminológicos”. In: Revista de Processo, v. 41/1986, jan.-mar./1986.

. O processo civil brasileiro entre dois mundos. Separata da Revista Forense, Rio de Janeiro, Ed. Forense, vol. 359.

. O processo civil contemporâneo: um enfoque comparativo. In: Revista Forense, n. 370, Separata, p. 55-59.

. O processo civil contemporâneo. Temas de direito processual. $9^{\mathrm{a}}$ ed., São Paulo: Saraiva, 2007.

. Temas de direito processual. 8 ser. São Paulo: Saraiva, 2004. . Tendências contemporâneas do direito processual civil. RePro 31/199.

BARROSO, Luís Roberto. Fundamentos teóricos e filosóficos do novo direito constitucional brasileiro (pós-modernidade, teoria clássica e pós-positivismo). In: BARROSO, Luís Roberto (Org.). A nova interpretação constitucional. 2. Ed. Rio de Janeiro: Renovar, 2006.

BAUR, Fritz. “O papel ativo do juiz”. In Revista de Processo, v. 27/1982, jul.-set./1982. 
BOBBIO, Norberto. L'etàdei diritti (tradução de Carlos Nelson Coutinho: A era dos direitos), Rio de Janeiro: Campus, 1992.

BEDAQUE, José Roberto dos Santos. Direito e Processo. Influência do direito material sobre o processo. 6 ed. São Paulo: Malheiros, 2011.

. Efetividade do processo e técnica processual, $3^{\mathrm{a}}$ ed. São Paulo: Malheiros, 2010.

. Garantia da Amplitude da produção probatória. In: TUCCI, José Rogério Cruz e (Coord.). Garantias Constitucionais no Processo civil. São Paulo: Revista dos Tribunais, 1999.

. Poderes instrutórios do juiz, 5a ed. São Paulo: Revista dos Tribunais, 2011. . Instrumentalismo e garantismo: visões opostas do fenômeno processual? In: ; CINTRA, Lia Carolina Batista; EID, Elie Pierre (Coords.). Garantismo processual: garantias constitucionais aplicadas ao processo, $1^{\mathrm{a}}$ ed. Brasília, DF: Gazeta Jurídica, 2016.

BONDIOLI, Luis Guilherme Aidar. Breves comentários ao novo Código de Processo Civil. In: WAMBIER, Teresa Arruda Alvim; DIDIER JR., Fredie; TALAMINI, Eduardo; DANTAS, Bruno (coord.). São Paulo: Revista dos Tribunais, 2015.

BONÍCIO, Marcelo José Magalhães. Princípios do processo no novo Código de Processo Civil. São Paulo: Saraiva, 2016.

BUENO, Cássio Scarpinella. Curso Sistematizado de Direito Processual. São Paulo: Saraiva, 2007, v. 1. . Manual de direito processual civil, v. ún. São Paulo: Saraiva, 2015. . Novo Código de Processo Civil anotado. São Paulo: Saraiva, 2015.

CANOTILHO, José Joaquim Gomes. O Ónus da prova na jurisdição das liberdades. In: Estudos Sobre Direitos Fundamentais. Coimbra: Coimbra, 2004.

CABRAL, Antonio do Passo. "O contraditório como dever e a boa-fé processual objetiva". In: Revista de Processo, vol. 126/2005, ago./2005.

CAMPOS, Eduardo Luiz Cavalcanti. O princípio da eficiência no processo civil brasileiro. Rio de Janeiro: Forense, 2018.

CAPPELlETTI, Mauro. Problemas de reforma do processo civil nas sociedades 
contemporâneas. In MARINONI, Luiz Guilherme (Coord.). $O$ processo civil contemporâneo. Curitiba: Juruá, 1994.

. Aspectos Políticos e Sociais do Processo Civil - Reformas e Tendências na Europa Ocidental e Oriental. In Mich L. Ver, vol. 69, 1971.

; GARTH, Bryant. Acesso à justiça. Tradução de Ellen Gracie Northfleet.

Porto Alegre: Fabris, 2002.

CARNELUTTI, Francesco. Como se faz um processo. Campinas: Servanda Editora, 2010.

. Diritto e processo. Napoli: Morano, 1958.

. Instituciones del proceso civil, v. I. Trad.: Santiago Sentis Melendo. Buenos

Aires: Librería "El Foro", 1997.

CHIOVENDA, Giuseppe. Instituições de Direito Processual Civil, v. I, $3^{\mathrm{a}}$ ed. Trad. $2^{\mathrm{a}}$ ed. italiana: J. Guimarães Menegale. São Paulo: Saraiva, 1969.

. Instituições de direito processual civil, v. II, $3^{\mathrm{a}}$ ed. Trad. $2^{\mathrm{a}}$ ed. italiana: J. Guimarães Menegale. São Paulo: Saraiva, 1969.

. Instituições de Direito Processual Civil, v. III, $2^{\mathrm{a}}$ ed. Trad. $2^{\mathrm{a}}$ ed. italiana:

J. Guimarães Menegale. São Paulo: Saraiva, 1965.

. "L'azione nel sistema dei diritti (1903)". In: Saggi di diritto processuale civile. Roma: Foro Italiano, 1930.

. Principios de Derecho Procesal Civil, t. I. Trad.: José Casáis Y Santaló.

Madrid: Editora Reus (S.A.), 1992.

CUNHA, Leonardo Carneiro da. "A previsão do princípio da eficiência no projeto do novo Código de Processo Civil brasileiro". In: Revista de Processo, v. 233/2014, jul./2014.

. Breves comentários ao novo Código de Processo Civil. Breves comentários ao novo Código de Processo Civil. In: WAMBIER, Teresa Arruda Alvim; DIDIER JR., Fredie; TALAMINI, Eduardo; DANTAS, Bruno (coord.). São Paulo: Revista dos Tribunais, 2015.

. Comentários ao Código de Processo Civil, v. III (arts. 188 ao 293). In: MARINONI, Luiz Guilherme (dir). ARENHART, Sérgio Cruz; MITIDIERO, Daniel (coord.). São Paulo: Revista dos Tribunais, 2016.

DIMITRI, Dimoulis. Além do ativismo e do minimalismo judicial no campo dos direitos 
fundamentais. Justificação jurídica de decisões e competência. In: FRANCISCO, José Carlos. Neoconstitucionalismo e atividade jurisdicional: do passivismo ao ativismo judicial. Belo Horizonte: Del Rey, 2012.

DINAMARCO, Cândido Rangel. A instrumentalidade do processo. $15^{\mathrm{a}}$ ed. São Paulo: Malheiros, 2013.

. A reforma da reforma, $6^{\text {a }}$ ed. São Paulo: Malheiros, 2003.

. Instituições de Direito Processual Civil, v. I, $8^{\text {a }}$ ed. São Paulo: Malheiros, 2016.

. Instituições de Direito Processual Civil, v. II, $7^{\mathrm{a}}$ ed. São Paulo: Malheiros, 2017

. Instituições de Direito Processual Civil, v. III, $7^{\mathrm{a}}$ ed. São Paulo: Malheiros, 2017.

. "O dever de motivar e a inteireza da motivação". In: Fundamentos do processo civil moderno, t. I, $6^{\text {a }}$ ed. São Paulo: Malheiros, 2010.

. “Os institutos fundamentais do direito processual”. In Fundamentos do processo civil moderno, t. I, $6^{\text {a }}$ ed. São Paulo: Malheiros, 2010.

. "O princípio do contraditório e sua dupla destinação". In: Fundamentos do processo civil moderno, t. I. São Paulo: Malheiros, 2010.

. Vocabulário de processo civil, $2^{\mathrm{a}}$ ed. São Paulo: Malheiros, 2014.

; LOPES, Bruno Vasconcelos Carrilho. Teoria geral do novo processo civil, $2^{\mathrm{a}}$ ed. Malheiros: São Paulo, 2017.

DIDIER JR., Fredie. Curso de Direito Processual Civil, v. 1, $18^{\mathrm{a}}$ ed. Salvador: JusPodivm, 2016.

FERRAJOLI, Luigi. Derecho y rázon: teoria del garantismo penal (com prologo de Norbeto Bobbio). Madrid: Trotta, 2011.

FERREIRA, Aurélio Buarque de Holanda. Novo Aurélio Século XXI: o dicionário da língua portuguesa, $3^{\mathrm{a}}$ ed. Rio de Janeiro: Nova Fronteira, 1999.

FRANCO, Marcelo Veiga. Processo justo - entre efetividade e legitimidade da jurisdição. Belo Horizonte: Editora Del Rey, 2016. 
GAJARDONI, Fernando da Fonseca. Flexibilização procedimental: um novo enfoque para o estudo do procedimento em matéria processual de acordo com as recentes reformas do CPC. São Paulo: Atlas, 2008.

. Técnicas de aceleração do procedimento. São Paulo: Lemos \& Cruz, 2003.

HOFFMAN, Paulo. Razoável duração do processo. São Paulo: Quartier Latin, 2006.

GOMES, Sérgio Alves. Os poderes do juiz na direção e instrução do processo civil. Rio de Janeiro: Forense, 1995.

GOMES FILHO, Antonio Magalhães. Direito à prova no processo penal. São Paulo: RT, 1997.

GRAUS, Eros Roberto. Por que tenho medo dos juízes (a interpretação/aplicação do direito e os princípios), $6^{\mathrm{a}}$ ed., $2^{\mathrm{a}}$ tiragem. São Paulo: Malheiros, 2014.

GRECO, Leonardo. Novas perspectivas da efetividade e do garantismo processo. In: MITIDIERO, Daniel; AMARAL, Guilherme Rizzo (Coords.). Processo civil - estudos em homenagem ao Professor Carlos Alberto Alvaro de Oliveira. São Paulo: Atlas, 2012.

. Instituições de direito processual civil, v. I, $5^{\mathrm{a}}$ ed. Rio de Janeiro: Forense, 2015.

GRINOVER, Ada Pellegrini. A iniciativa instrutória do juiz no processo penal acusatório. Revista Forense 347/3-10.

. Os princípios constitucionais e o Código de Processo Civil. São Paulo: Bushatsky, 1975. . O processo em evolução. Rio de Janeiro: Forense Universitário, 1996.

GUSMÃO, Manoel Aureliano. Processo civil e comercial. São Paulo: Saraiva, 1924, v. II. HOUAISS, Antônio; VILLAR, Mauro de Salles. Dicionário Houaiss da língua portuguesa, $1^{\text {a }}$ ed. Rio de Janeiro: Objetiva, 2001.

JARDIM, Afrânio Silva. A pretensão processual. O Estado de S. Paulo, 26.02.1984. . Da publicização do processo civil. Rio de Janeiro: Liber Juris, 1982.

KARAM, Munir. “Ônus da prova: noções fundamentais. RePro 17/51.

LACERDA, Galeno. Despacho saneador. Porto Alegre: Livraria Sulina, 1953.

LEONEL, Ricardo de Barros. Garantismo e direito processual constitucional. In: 
BEDAQUE, José Roberto dos Santos; CINTRA, Lia Carolina Batista; EID, Elie Pierre (Coords.). Garantismo processual: garantias constitucionais aplicadas ao processo, $1^{\mathrm{a}} \mathrm{ed}$. Brasília, DF: Gazeta Jurídica, 2016.

LESSONA, Carlos. Teoria general de la puebra em derecho civil. Trad. Espanhola. Madri: Reus, 1957, vol. I.

LIEBMAN, Enrico Tullio. Estudos sobre o processo civil brasileiro. São Paulo: Bestbook, 2001.

. Manual de direito processual civil. Tradução e notas de Cândido Rangel Dinamarco. 3 ed. São Paulo: Malheiros, v. I, 2005.

LOPES, Maria Elizabeth de Castro. O juiz e o princípio dispositivo. São Paulo: Revista dos Tribunais, 2006.

LUCON, Paulo Henrique dos Santos. "Segurança jurídica no Código de Processo Civil de 2015”. In: LUCON, Paulo Henrique dos Santos; APRIGLIANO, Ricardo de Carvalho; SILVA, João Paulo Hecker da; VASCONCELOS, Ronaldo; ORTHMANN, André (coord.). Processo em jornadas. Salvador: JusPodivm, 2016.

SILVA, José Afonso da Silva. Curso de Direito Constitucional Positivo. 25 ed. rev. e atual. São Paulo: Malheiros, 2005.

MACHADO, Marcelo Pacheco. A correlação no processo civil-relações entre demandas e tutela jurisdicional. Salvador: JusPodivm, 2015.

. Incerteza e processo. São Paulo: Saraiva, 2013.

MARCATO, Antonio Carlos. Algumas considerações sobre a crise da justiça, pp.1-49, 2010. Disponível em: <http://www.marcatoadvogados.com.br/wpcontent/uploads/2015/07/arquivo66.pdf> . Acesso em 19.07.2018.

. O processo monitório brasileiro. São Paulo: Malheiros, 1998.

. “Preclusões: limitação ao contraditório?”. In: Revista de Processo, vol. 17/1980, jan.-mar./1980.

Procedimentos especiais, 16 ed. São Paulo: Atlas, 2016.

MARINONI, Luiz Guilherme; MITIDIERO, Daniel. O projeto do CPC: críticas e propostas, $2^{\mathrm{a}}$ t. São Paulo: Revista dos Tribunais, 2010.

; ARENHART, Sérgio Cruz; MITIDIERO, Daniel. Novo curso de processo 
civil: teoria do processo civil, v. 1, 2a ed. São Paulo: Revista dos Tribunais, 2016.

MARQUES, José Frederico. Instituições de Direito Processual Civil, v. III, $4^{\mathrm{a}}$ ed. Rio de Janeiro: Forense, 1972.

. Manual de direito processual civil. 7 ed. São Paulo: Saraiva, 1980.

MARTINS-COSTA, Judith. A boa-fé no direito privado. São Paulo: Marcial Pons, 2015.

MIRANDA, Vicente. Poderes do juiz no processo civil brasileiro. São Paulo: Saraiva, 1993.

MEJIAS, Lucas Britto. In: BEDAQUE, José Roberto dos Santos; CINTRA, Lia Carolina Batista; EID, Elie Pierre (Coords.). Garantismo processual: garantias constitucionais aplicadas ao processo, $1^{\mathrm{a}}$ ed. Brasília, DF: Gazeta Jurídica, 2016.

MITIDIERO, Daniel. A colaboração no processo civil - pressupostos sociais, lógicos e éticos, $3^{\mathrm{a}}$ ed. São Paulo: Revista dos Tribunais, 2015.

NAGAO, Paulo Issamu. O papel do juiz na efetividade do processo civil contemporâneo. São Paulo: Malheiros, 2016.

NERY JUNIOR, Nelson. Princípios do processo na Constituição Federal. São Paulo: Revista dos Tribunais, 2016.

; NERY, Rosa Maria de Andrade e. Código de Processo Civil comentado, $16^{\mathrm{a}}$ ed. São Paulo: Revista dos Tribunais, 2016.

OLIVEIRA, Carlos Alberto Alvaro. Do formalismo no processo civil - Proposta de um formalismo-valorativo, $4^{\mathrm{a}}$ ed. rev. atual. e aum., São Paulo: Saraiva, 2010.

- “Garantia do contraditório". In: TUCCI, José Rogério Cruz e (coord.).

Garantias constitucionais do processo civil. São Paulo: Revista dos Tribunais, 1999.

. O formalismo valorativo no confronto com o formalismo excessivo. Revista Forense, v. 388, Separata, p. 13-14.

. Poderes do juiz e visão cooperativa do processo. In: Revista da Faculdade de Direito da Universidade de Lisboa, v. XLIV, n. 1 e 2, 2003.

. Teoria e prática da tutela jurisdicional. Rio de Janeiro: Forense, 2008.

; MITIDIERO, Daniel. Curso de processo civil. São Paulo: Atlas, 2010, v. 1.

ONODERA, Marcus Vinicius Kiyoshi. "Breves anotações sobre o gerenciamento do 
processo (case management) e o novo Código de Processo Civil”. In: LUCON, Paulo Henrique dos Santos; APRIGLIANO, Ricardo de Carvalho; SILVA, João Paulo Hecker da; VASCONCELOS, Ronaldo; ORTHMANN, André (Coords.). Processo em jornadas. Salvador: JusPodivm, 2016.

PONTES DE MIRANDA, Francisco Cavalcanti. Comentários ao Código de Processo Civil. 2 ed. Rio de Janeiro: Ed. Forense, t. II.

. Tratado de direito privado, t. I, $4^{\text {a }}$ ed. São Paulo: Revista dos Tribunais, 1983.

PORTANOVA, Rui. Princípios no processo civil, $7^{\mathrm{a}}$ ed. Porto Alegre: Livraria do Advogado, 2008.

PUOLI, José Carlos Baptista. Os poderes do juiz e as reformas da lei processual brasileira, dissertação de mestrado apresentada na Faculdade de Direito da Universidade de São Paulo, 2000.

RAMOS, Elival da Silva. Ativismo Judicial: parâmetros dogmáticos. São Paulo: Saraiva, 2010, p. 216.

RIGHI, Ivan Ordine. Os poderes do juiz. In Jurisprudência Brasileira, v. 169.

ROCHA, Cesar Asfor. A luta pela efetividade da jurisdição. São Paulo: Revista dos Tribunais, 2007.

ROQUE, André Vasconcelos. "Contraditório participativo: evolução, impactos no processo civil e restrições”. In Revista de Processo, v. 279/2018, maio/2018.

SANTOS, Moacyr Amaral. Primeiras Linhas do Direito Processual. 27 ed. São Paulo: Saraiva, 2010, v. I, p. 21-22.

. Prova Judiciária no Cível e Comercial. 5 ed., v. I. São Paulo: Saraiva, 1983.

SCHREIBER, Anderson. A proibição do comportamento contraditório - tutela da confiança e venire contra factum proprium, $2^{\mathrm{a}}$ ed. Rio de Janeiro: Renovar, 2007.

SENADO FEDERAL. Código de Processo Civil e normas correlatas, $7^{\mathrm{a}}$ ed. Brasília: Coordenação de Edições Técnicas, 2015.

SICA, Heitor Vitor Mendonça. "Algumas implicações do novo conceito de sentença no Processo Civil, de acordo com a Lei $\mathrm{n}^{0}$ 11.232/2005”. In: CARMONA, Carlos Alberto. Reflexões sobre a Reforma do Código de Processo Civil. São Paulo: Atlas, 2007. 
- O direito de defesa no processo civil brasileiro - um estudo sobre a posição do réu. São Paulo: Atlas, 2011. . Preclusão no processo civil. São Paulo: Atlas, 2006.

SILVA, Ovídio A. Baptista da. Curso de processo civil, v. 1, $6^{\mathrm{a}}$ ed. São Paulo: Revista dos Tribunais, 2003.

SILVEIRA, João José Custódio da. O juiz e a condução equilibrada do processo. São Paulo: Saraiva, 2012.

SOUZA, André Pagani de. "Princípios constitucionais e vedação das decisões-surpresa". In: LUCON, Paulo Henrique dos Santos; APRIGLIANO, Ricardo de Carvalho; SILVA, João Paulo Hecker da; VASCONCELOS, Ronaldo; ORTHMANN, André (Coords.). Processo em jornadas. Salvador: JusPodivm, 2016.

TARUFFO, Michele. Il diritto all prova nel processo civile. In: Rivista di Diritto Processuale, 1984. . Studi sulla rilevanza della prova. Padova: Cedam, 1970.

THEODORO JÚNIOR, Humberto. Curso de Direito Processual Civil, v. I, $57^{\mathrm{a}}$ ed. Rio de Janeiro: Forense, 2016.

. O processo justo o juiz e seus Poderes Instrutórios na Busca da Verdade Real. In: Revista Dialética de Direito Processual, n. 80, nov. 2009.

. Prova - princípio da verdade real - poderes do juiz - ônus da prova e sua eventual inversão - provas ilícitas - prova e coisa julgada nas ações relativas à paternidade (DNA). In: Revista de Direito Privado, São Paulo, v. 3, n. 17, p. 9-28, jan./mar. 2004.

. "Saneamento e organização do processo. Gestão compartilhada do processo justo. Recurso. Não ocorrência de preclusão”. In: YARSHELL, Flávio Luiz; BEDAQUE, José Roberto dos Santos; SICA, Heitor Vitor Mendonça. Estudos de Direito Processual Civil em homenagem ao Professor José Rogério Cruz e Tucci. Salvador: JusPodivm, 2018.

; NUNES, Dierle José Coelho. "Uma dimensão que urge reconhecer ao contraditório no direito brasileiro: sua aplicação como garantia de influência, de não surpresa e de aproveitamento da atividade processual". In: Revista de Processo, vol. 168/2009, fev./2009.

TUCCI, José Rogério Cruz e. “Garantia do processo sem dilações indevidas”. In: TUCCI, 
José Rogério Cruz e (coord.). Garantias constitucionais do processo civil. São Paulo: Revista dos Tribunais, 1999.

. Tempo e processo - uma análise empírica das repercussões do tempo na fenomenologia processual (civil e penal). São Paulo: Revista dos Tribunais, 1998.

VINCENZI, Brunela Vieira de. A boa-fé no processo civil. São Paulo: Atlas, 2003.

TALAMINI, Eduardo. A nova disciplina do agravo e os princípios constitucionais do processo. In Revista de informação legislativa, v. 33, n. 129, jan./mar. 1996.

. Prova emprestada no processo civil. In Revista de informação legislativa, v. 35, n. 140, out./dez. 1998.

WAMBIER, Luiz Rodrigues; TALAMINI, Eduardo. Curso avançado de processo civil: teoria geral do processo, v. 1, 16ª ed. São Paulo: Revista dos Tribunais, 2016. . Curso avançado de processo civil: cognição jurisdicional (processo comum de conhecimento e tutela provisória), v. 2, 16 a ed. São Paulo: Revista dos Tribunais, 2016. WAMBIER, Teresa Arruda Alvim. O ônus da prova. Revista Jurídica Consulex, Brasília: Consulex, n. 200, mai.2005.

YARSHELL, Flavio Luiz. Tutela jurisdicional, 2a ed. São Paulo: DPJ Editora, 2006. . Antecipação da prova sem o requisito da urgência e direito autônomo à prova. São Paulo: Malheiros, 2009. 